\title{
Earliest occurrence of lophogastrid mysidacean arthropods (Crustacea, Eucopiidae) from the Anisian Luoping Biota, Yunnan Province, China
}

\author{
Rodney M. Feldmann, ${ }^{1}$ Carrie E. Schweitzer, ${ }^{2}$ Shixue Hu, ${ }^{3,4}$ Jinyuan Huang, ${ }^{3,4}$ Changyong Zhou, ${ }^{3,4}$ \\ Qiyue Zhang, ${ }^{3,4}$ Wen Wen, ${ }^{3,4}$ Tao Xie, ${ }^{3,4}$ Frederick R. Schram, ${ }^{5}$ and Wade T. Jones ${ }^{1}$ \\ ${ }^{1}$ Department of Geology, Kent State University, Kent, OH 44240 USA 〈rfeldman@kent.edu〉 \\ ${ }^{2}$ Department of Geology, Kent State University at Stark, 6000 Frank Avenue NW, North Canton, OH 44720, USA 〈cschweit@kent.edu〉 \\ ${ }^{3}$ Chengdu Institute of Geology and Mineral Resources, Chengdu, 610081, China 〈hushixue@ hotmail.com〉 \\ ${ }^{4}$ Chengdu Center of China Geological Survey, No. 2, N-3-Section, First Ring, Chengdu 61008, China \\ ${ }^{5}$ Department of Invertebrate Paleontology, Burke Museum of Natural History, University of Washington, Seattle WA 98195 USA \\ $\langle$ fschram@whidbey.com $\rangle$
}

\begin{abstract}
Tiny, pelagic arthropods from the Anisian Luoping Biota exposed in two quarries near Luoping, Yunnan Province, China, represent the numerically most abundant organisms in the assemblage. They form the basis for definition of two, and possibly three, species referred to the order Lophogastrida, family Eucopiidae. Yunnanocopia grandis new genus new species and Y. longicauda n. gen. new species represent the oldest occurrence of mysidaceans in the fossil record. Their anatomy allies them with the Ladinian species Schimperella acanthocercus Taylor, Schram, and Shen, 2001, from Guizhou Province, China, which previously was thought to be the oldest lophogastrid, and with extant species of Eucopiidae. Their appearance in the Anisian represents one additional element of the early faunal radiation within the Luoping Biota following the end-Permian extinction event. Presence of well-preserved oostegites, along with other morphological features, documents a conservative bauplan expressed in Eucopiidae.
\end{abstract}

\section{Introduction}

Mysidaceans are a group of shrimplike peracarid crustaceans. They are arrayed into three orders: Mysida, Lophogastrida, and Stygiomysida (Meland and Willassen, 2007; Wittmann et al., 2014). The earliest record of mysidaceans is in the Triassic of France (Bill, 1914) and China (Taylor et al., 2001). South China is famous for widespread exposures of marine deposits from Late Palaeozoic to Late Triassic, and the area is well known for fossil Lagerstätten with exceptional preservation of diverse fossils. Despite intensive excavations over decades, only a single mysidacean taxon, Schimperella acanthocercus Taylor, Schram, and Shen, 2001, has been reported from the Ladinian Stage of the Middle Triassic in South China. Here we report the discovery of a new mysidacean assemblage from the Anisian Stage of the Middle Triassic Luoping biota in SW China. This occurrence represents the oldest known assemblage of mysidaceans.

The Luoping biota is a typical conservation Lagerstätte with exceptional preservation. Mysidaceans are the most numerous animals within the Luoping biota (Hu et al., 2011). More than ten thousand individuals have been recovered so far. Associated fossils include marine reptiles, fish, bivalves, gastropods, echinoderms, ammonoids, lingulid brachiopods, plants, and other arthropods. In addition to the mysidaceans, horseshoe crabs (Zhang et al., 2008), isopods (Fu et al., 2010), lobsters (Feldmann et al., 2012), and shrimp (Schweitzer et al.,
2014) have been described. Thylacocephalans and a single myriapod are currently under study. The depositional environment of the Luoping biota is interpreted as a semi-closed intraplatform basin, and the exceptional preservation of fossils is interpreted to have been due to anoxia of bottom water and microbial sealing (Hu et al., 2011; Luo et al., 2013).

The material studied here was recovered from the middle part of Member II of the Guanling Formation at two quarries: the Dawazi Quarry (Quarry 1 of Feldmann et al., 2016 [2015]) and the Shangshikan Quarry (Quarry 2 of Feldmann et al., 2016 [2015]), Luoping County, Yunnan Province, SW China (Fig. 1). The interval containing the fossil mysidaceans is approximately $16 \mathrm{~m}$ thick, and is primarily comprised of thinly laminated micritic limestone alternating with thin- to moderately thickbedded silty limestone. Fossil mysidaceans were obtained by splitting finely laminated micritic limestone. Most individuals are preserved as carbonized specimens, compressed in dorsal or lateral views on the bedding surface. A few individuals bear intestines preserved in 3-D configuration. Although several hundred individuals were examined in the course of this study, 25 were selected as type specimens for inclusion in this work.

In addition to describing the new species of lophogastrid mysidaceans representing the oldest known occurrence of the group, the presence of swarms of the organisms and the association of multiple species in single occurrences permits speculation on the lifestyle of the animals. 


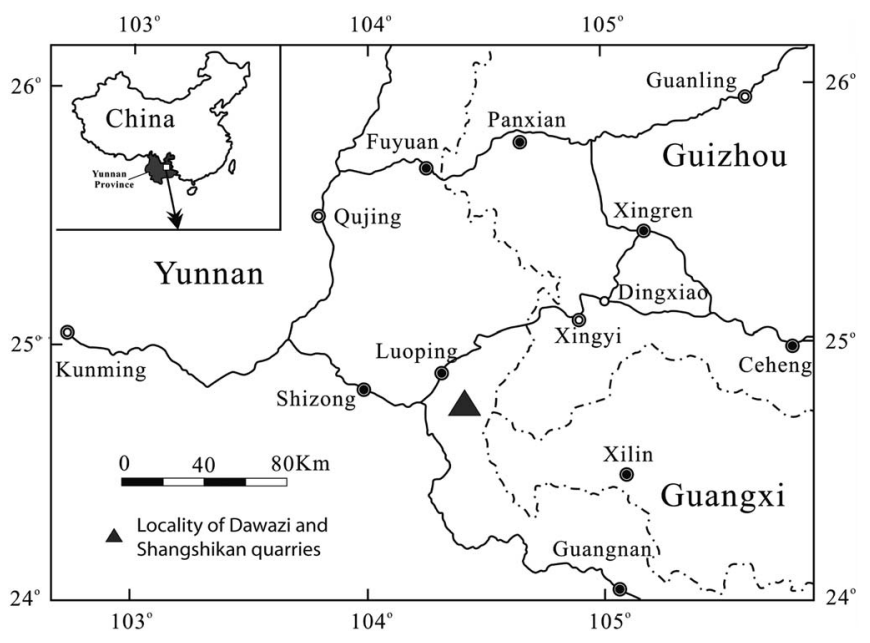

Figure 1. Map and collecting localities for mysidacean crustaceans.

\section{Materials}

Repository and institutional abbreviation.-Specimens in this study are deposited in the Invertebrate Paleontology Collection, Chengdu Institute of Geology and Mineral Resources, Chengdu, Sichuan Province, China, bearing the acronym LPI.

\section{Systematic paleontology}

Class Malacostraca Latreille, 1802

Order Lophogastrida Boas, 1883

Family Eucopiidae Sars, 1885

Diagnosis.-Carapace large, last 2 or 3 thoracic somites exposed dorsally. Rostrum obtuse. Eyes normally developed. Antennal (antenna 2) scale with apical suture, outer margin smooth, without setae, with or without terminal spine. Labrum symmetric. Mandible; left mandible lacinia mobilis well developed, reduced, or absent; right mandible armed with fixed cusp in position of the lacinia mobilis; spine row absent, molar process well developed.

1st maxilliped exopod small, unarticulated. 2nd thoracopod developed as a gnathopod, exopod reduced. 3rd thoracopod forming a gnathopod. 4th thoracopod forming a gnathopod. 3rd-8th thoracopod endopods with distinct carpus and propodus, propodus unsegmented. Branchiae on thoracopods present. Marsupium composed of seven pairs of oostegites.

Pleonal pleural plates absent. 6th and 7th pleonal somites [pleomeres] fused. Female pleopods biramous. Uropod endopod setose around entire margin, statocyst absent; exopod with distal articulation [diaeresis], outer margin entire, terminating in distal spines. Telson apex entire to lateral margins constricted (adapted from Meland, 2002; square brackets embrace emendations).

Remarks.-Meland (2002) published an illustrated, interactive key to eight extant families included within order Mysidacea. The key is based upon a broad spectrum of characters and is illustrated to clarify terminology. Among these, features of the antennae, carapace, pleon, telson, and appendages are preserved on specimens from the Luoping Biota. In fact, a sufficient number of features are present that specimens can be placed within families with a high degree of confidence. This plexus of characters is entirely compatible with placement within Eucopiidae and excludes placement in other morphologically similar families. Thus, Eucopiidae now includes three fossil genera: Eucopia Dana, 1852; Schimperella Bill, 1914; and Yunnanocopia new genus.

Three families of the eight considered by Meland (2002) to be united within Mysidacea keyed out as most similar morphologically: Eucopiidae, Lophogastridae Sars, 1870, and Mysidae Haworth, 1825. Lophogastridae is characterized by a plate-like rostrum and an antennal scale with a serrated outer margin, as seen in the fossils. Some subfamilies of Mysidae also key out close to Eucopiidae. The marsupium of Mysinae Haworth, 1825, within Mysidae, is composed of only two pairs of oostegites, whereas that in the present specimens has at least six, and probably seven pairs. Similarly, another mysid subfamily, Mysidellinae Norman, 1892, is characterized by an elongate rostrum, a marsupium with three pairs of oostegites, a cleft telson, and an exopod lacking a diaeresis, none of which are seen in the new specimens. Thus, Eucopiidae is the only family that can accommodate the Luoping specimens.

Meland (2002) considered Mysidacea as an order subdivided into families but without subordinal arrangement. Hessler (1969), among others, also considered Mysidacea to be of ordinal rank, but subdivided the order into two suborders: Mysida Boas, 1883, and Lophogastrida Boas, 1883, including Eucopiidae.

As an alternative to the higher level classifications of Hessler (1969), Meland (2002), and others, other higher level classifications of eucopiids and related forms have elevated Lophogastrida and Mysida to the level of order (Schram, 1986; Martin and Davis, 2001; Meland and Willassen, 2007; Wittmann et al., 2014; Meland et al., 2015); however, the concept of Eucopiidae is essentially unchanged. The diagnosis of Eucopiidae presented by Wittmann et al. (2014) generally conforms to that of Meland (2002), with Eucopiidae as a family within Lophogastrida instead of Mysidacea. The nature of preservation of the Luoping material is such that it is not possible to assess the higher-level ranks of Mysidacea sensu lato in any greater detail. Therefore, we follow the most recent classification placing Eucopiidae within order Lophogastrida. We retain the diagnosis of Meland (2002) for Eucopiidae because it permits clear placement of fossil material within the family, utilizing features preserved on fossil specimens, which lack many morphological features commonly used in other biological classifications.

\section{Yunnanocopia new genus}

Type species.-Yunnanocopia grandis new species, by original designation.

\section{Other species._Yunnanocopia longicauda new species}

Diagnosis.-Antennal scale ovate to lanceolate with an acute tip; antennular segments are stout with first segment larger 
than second and third; precervical grooves inclined posterolaterally and do not cross midline; cervical groove concave forward; two or three thoracic segments exposed dorsally; pleonal pleurae strongly reduced or absent; telson and uropods lack any indication of having been setose.

Etymology.-The generic name refers to Yunnan, the province from which the specimens were collected, and the Latin copia $=$ abundance, in reference to the abundance of specimens referable to the genus. The gender is feminine.

Remarks.-The specimens collected from the Luoping Biota represent taxa that can confidently be assigned to a new genus. Previously, Taylor et al. (2001) described Schimperella acanthocercus from Triassic rocks in Guizhou, China. Species of Schimperella differ in several ways from the Luoping material sufficiently to warrant description of a new genus. Schimperella Bill, 1914, was based upon two species from the Triassic of France: $S$. beneckei, the type species by subsequent designation of Hessler (1969), and S. kessleri. The unique nature of S. kessleri has been questioned (Taylor et al., 2001). Certainly the illustrations of the species (Bill, 1914, pl. 16, figs. 3, 4) suggest that it may be the female counterpart of $S$. beneckei. In addition, Schimperella spp. have been reported from the Middle Triassic Meride Limestone in northeastern Italy (Largi and Tintori, 2007) and from the Middle Triassic (middle Anisian) Strelovec Formation in Slovenia (Križna and Hitij, 2010). This latter occurrence might be shown to be more or less contemporaneous with the Luoping occurrences; however, that has yet to be tested.

Schimperella kessleri exhibits a well-developed marsupium, whereas the type species appears to be a male. Regardless, species of Schimperella are characterized by an extremely large, obovate antennal scale; slender basal antennular segments; a weak, transverse precervical groove; transverse cervical groove; carapace covering nearly all thoracic segments dorsally; pleonal pleura that are moderately well developed; and setose telson and uropods. By contrast, the antennal scale of Yunnanocopia spp. is ovate with an acute tip, the antennular segments are stout, the precervical grooves are inclined posterolaterally, the cervical groove is concave forward, two or three thoracic segments are exposed dorsally, pleonal pleurae are strongly reduced or absent, and the telson and uropods lack any indication of having been setose. Thus, assignment of the lophogastrids from the Luoping Biota to a new genus seems fully warranted.

Yunnanocopia grandis new species

Figures 2.1-2.7, 3.1-3.6, 4.1-4.6

Diagnosis.-Third element of antennular base shorter than second; antennal scale weakly convex laterally, ovoid, longer than wide; endophragmal skeleton narrows posteriorly; at least six pairs of oostegites form prominent marsupium; pleonal tergites irregularly nodose; pleura not evident; telson spatulate; uropods long, flabellate.

Description.-Large, stout eucopiids. Antennules biflagellate; antennular base with first element longer than wide, rectangular, outer and inner margins weakly convex; second segment short, about as wide as long, rectangular; third segment shorter, wider than long, narrowing axially, extends nearly to tip of antennal scale. Antennular flagellae of equal diameter, but two different lengths; inner one is much shorter, directed straight forward. Antenna longer than the antennules. First antennal segment longer than wide, rectangular; second segment apparently rectangular, about as wide as first segment but shorter; flagellum more stout than antennular ones. Antennal scale weakly convex laterally, ovoid, longer than wide; thickened rim on outer margin. Basal element of antennal scale equidimensional, outer margin weakly convex, inner margin apparently broken, distal margin sinuous, with a small spine on outer corner.

Cephalothorax longer than wide, anterior margin obscured; weakly convex laterally; deeply concave posteriorly, rimmed, posterolateral corner projected as rounded, posterolaterally directed flange; rostrum inferred to be short, triangular. Cervical groove rims anterolateral margin and curves from anterolateral margin posteriorly at $45^{\circ}$ angle, then extends straight to axis at much lower angle to midline; as it approaches midline, it curves and parallels midline for short distance before crossing midline. Precervical groove intersects cervical groove laterally, then arcs concave forward and traverses obliquely about one-quarter the distance toward axis, defining hepatic region; expressed as grooves on the holotype. Cephalic region short. No evidence of lateral rim or any ornamentation posterior to cervical groove. Two or possibly three thoracomeres not covered by carapace dorsally (40749). Underside of anterior part of cephalothorax rimmed.

Endophragmal skeleton well calcified, six apodemes visible, straight, inclined posterolaterally from midline; seven pairs of coxal holes evident, all posterior to cervical groove; endophragmal skeleton narrows posteriorly, widest at position of third and fourth coxal holes.

Marsupium well developed on female specimens. Right oostegites ovate, posterior margin concave forward, with thickened rim, posterior-most oöstegite apparently arising on last thoracomere, extending from position of basal elements of thoracopods over half the distance across preserved portion of animal; six are preserved. Left oostegites with convex-forward, thickened anterior margin. Left oostegites overlap the right ones.

Six pleonites, first five about equal length, width decreases slightly posteriorly; sixth pleonite longer than the fifth; tergites irregularly nodose, rimmed along posterior margin of each pleonite, lateral margins rounded, bordered by thickened rim. In ventral aspect pleonites are strongly calcified anteriorly and axially, flaring anteriorly into sharp processes. Pleopods visible on pleonites 3-6, flagellate, multiarticulate, nearly as long as somite width; basal element ovate, slightly longer than wide.

Telson spatulate, tapers slightly posteriorly, anteriorly not quite as wide as sixth pleonal somite, axially sulcate from anterior end nearly to termination dorsally and with broad granular ridge arising proximally, bifurcating distally, on ventral side; weakly rimmed marginally; distally smoothly rounded, lateral margins of telson appear granular.

Uropods long, flabellate, exopod markedly longer than endopod, diaeresis of exopod lies posterior to end of telson, two nodes at about midwidth of diaeresis (40749). Endopod flabellate, extending to tip of telson. 


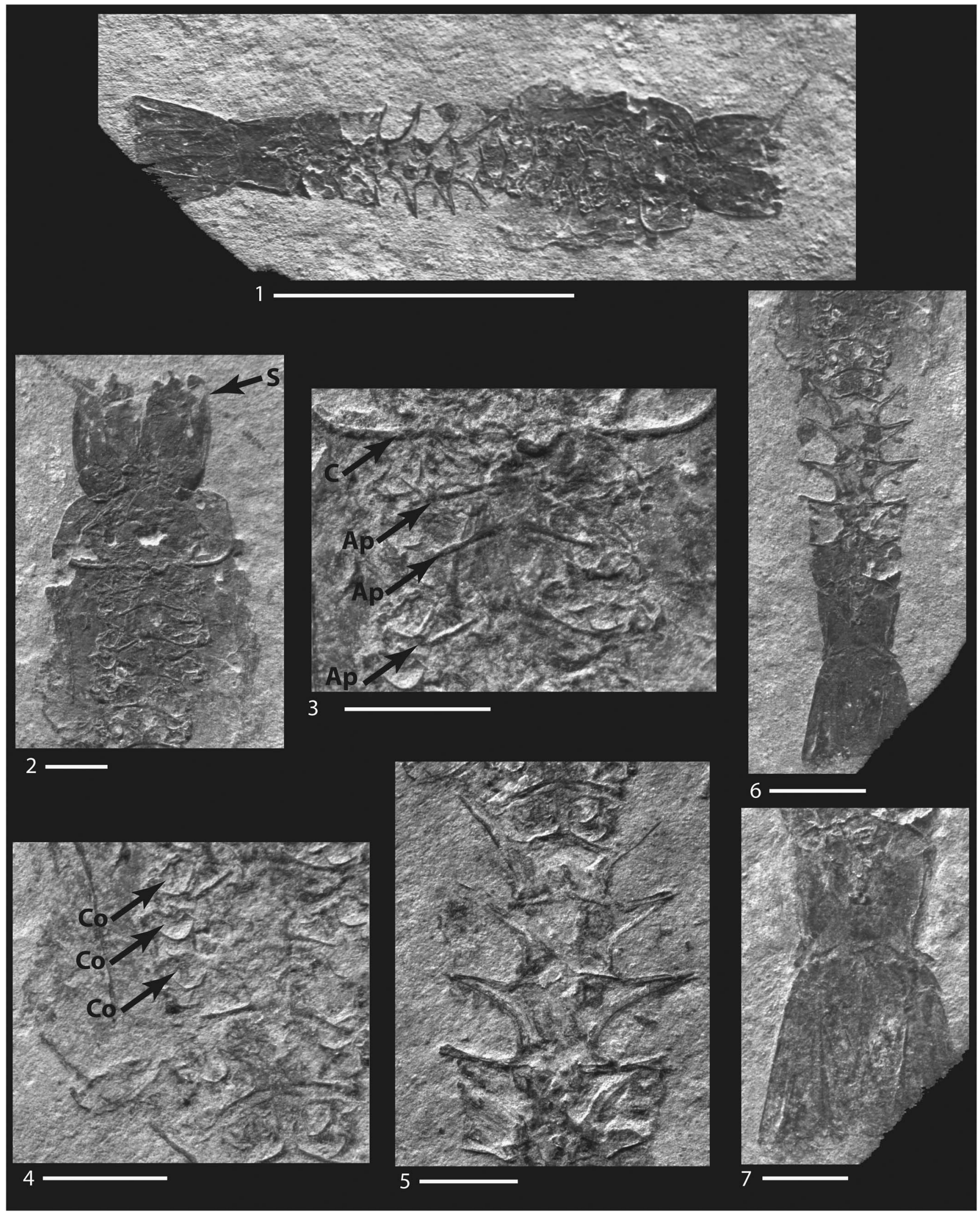

Figure 2. Yunnanocopia grandis new genus new species, LPI-41683, paratype: (1) entire animal; (2) anterior of body, S = antennal scale; (3) thoracic somites, $\mathrm{C}=$ cervical groove, $\mathrm{Ap}=$ apodemes of thoracic somites; (4) posterior end of thorax, $\mathrm{Co}=$ coxae of thoracic appendages; (5) closeup of pleonal somites; (6) pleon including telson and uropods; (7) pleonal somite 6 , telson, and uropods. Scale bar $1=1 \mathrm{~cm}$; scale bar $6=2 \mathrm{~mm}$, remaining scale bars $=1 \mathrm{~mm}$. 


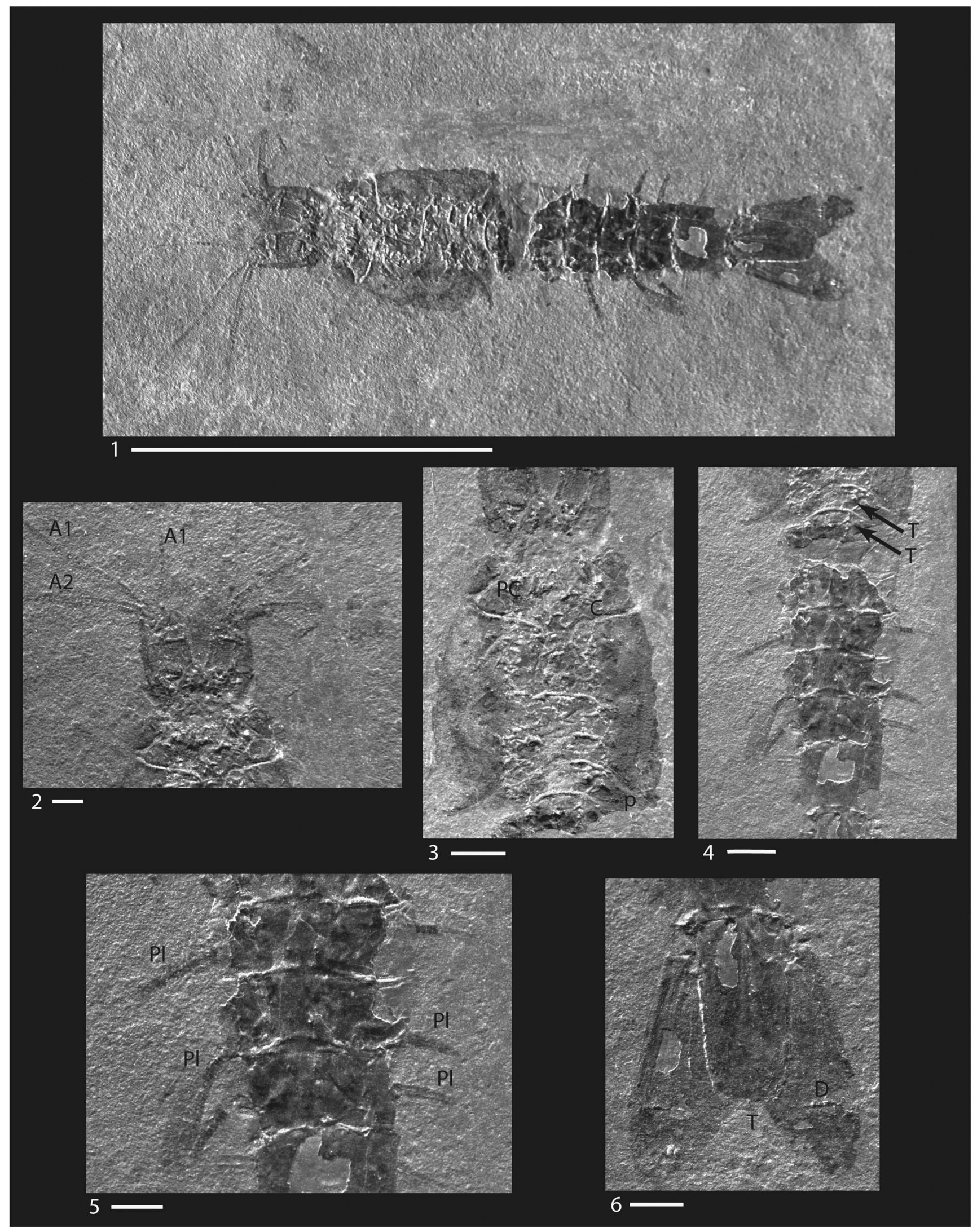

Figure 3. Yunnanocopia grandis new genus new species, LPI-40749, holotype: (1) entire animal; (2) anterior view, A1 = antennules, A2 = antennae; (3) thorax, $\mathrm{PC}=$ pre-cervical groove, $\mathrm{C}=$ cervical groove, $\mathrm{p}=$ posterior margin of carapace, note at least 2 thoracic somites not covered by carapace; (4) posterior thorax and pleon, $\mathrm{T}=$ thoracic somites not covered by carapace; (5) pleonal somites with pleopods (Pl); (6) Telson (T) and uropods showing diaeresis $(\mathrm{D})$ on exopod. Scale bar $1=1 \mathrm{~cm}$; remainder $=1 \mathrm{~mm}$ 

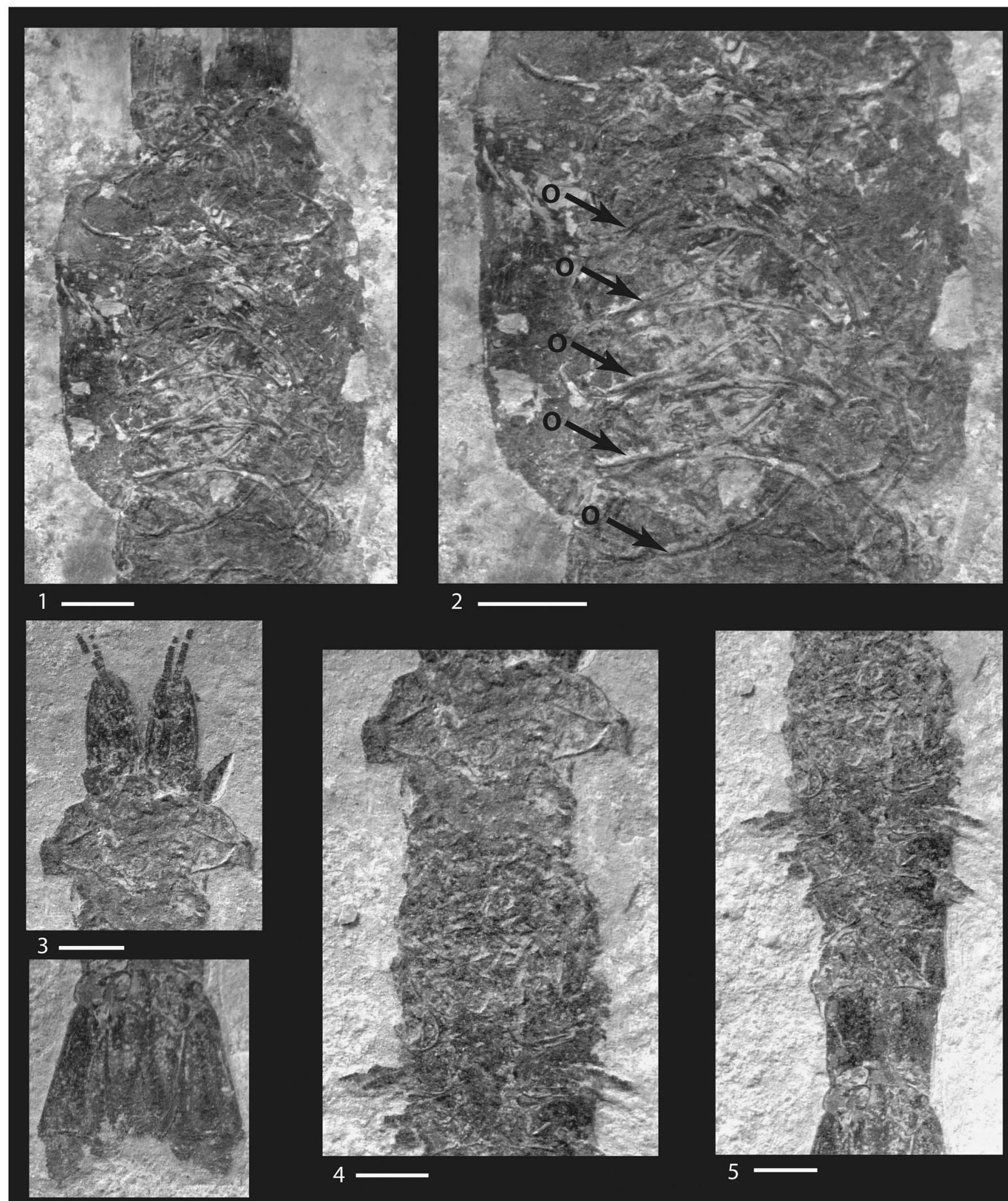

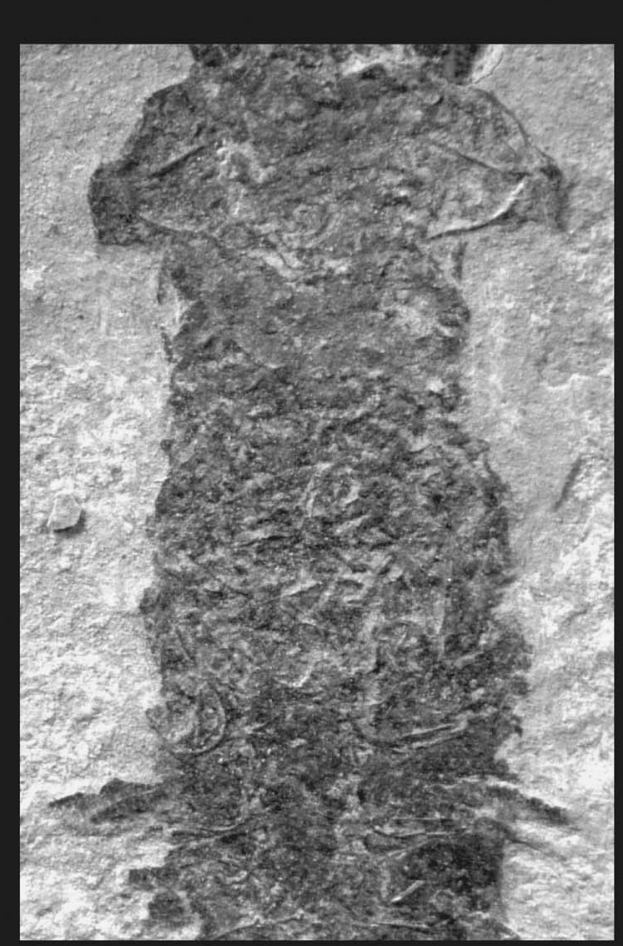

4

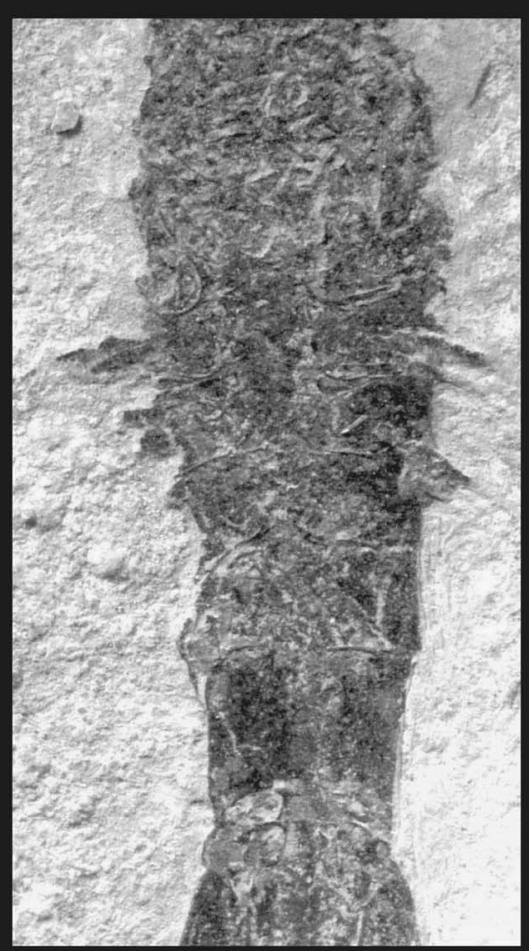

5

6

Figure 4. Yunnanocopia grandis new genus new species: (1-2) LPI-33341, paratype, (1) anterior view of thorax, cervical groove, and basal elements of antennal scale, (2) thorax with oostegites (O); (3-6) LPI-41689, paratype, (3) anterior view showing cervical groove and antennal scales; (4) thorax and anterior pleon; (5) pleon with basal elements of pleopods; (6) telson and uropods. Scale bars $=1 \mathrm{~mm}$. 
Etymology.-The trivial name refers to the relatively large size of specimens referred to this species.

Types.-Holotype, LPI-40749, and paratypes LPI-41683, 41684, 41648, 41689, 33341, and 41390.

Remarks.-Specimens referred to Yunnanocopia grandis are preserved in both dorsal and ventral aspect. The anterior appendages and the cephalic region tend to be well represented, and the thoracic region is poorly exposed or absent axially, but well represented laterally. Pre-cervical and cervical grooves are well impressed, and the pleon and tail elements are well preserved. Several specimens exhibit parts of the endophragmal skeleton that bears a close resemblance to that seen in Schimperella acanthocercus, consisting of biconcave forward rays emanating from the midline. However, the rays are somewhat thicker on S. acanthocercus. Pleonal sternites on both species form triangular extensions from the axial region; the anterior and posterior rays of those of $S$. acanthocercus project axially at the same angle, whereas those of $Y$. grandis do not. The anterior ray lies in a nearly transverse position, and the posterior ray is directed posteriorly. Ventral views of the sternites of $S$. acanthocercus are not in evidence because those specimens tend to be preserved in dorsal or lateral aspect.

\section{Yunnanocopia longicauda new species} Figures 5.1-5.6, 6.1-6.6, 7.1-7.6, 9

Diagnosis. - Long, slender eucopiids. Third article of antennular base longer than second; antennal scales lanceolate, sharp tipped; rostrum long, slender; endophragm narrow, apparently straight sided; pleonal tergites appear to be smooth; pleura strongly reduced; telson much longer than wide, margins convex, narrowing slightly posteriorly; uropods very long, slender.

Description.-Antennular base with first segment longer than wide, rectangular, about two-thirds as wide as antennal scale; second article rectangular, wider than long; third article tapering distally, wider than long, longer than second article; antennular flagella stout. Antennal scales lanceolate, sharp tipped, thickened on smooth outer margin. Antennal flagellum(?) lies ventrally below antennal scale. In lateral view dorsal surface of antennal scale is arcuate, much longer than wide. There may be a diaeresis on the antennal scale. Specimen 41569 shows breaks on both sides that could be where diaeresis is positioned. Other specimens show what might be breaks, but 41770 does not show the diaeresis, so its presence is equivocal.

Rostrum(?) long. Precervical grooves extend anteroventrally and then curve posteroventrally. Cervical groove a concave-forward arc all the way across the carapace. Eyes on very short stalks, large; stalks about $0.33 \mathrm{~mm}$ long. Six or seven thoracomeres visible in ventral view. Six or seven apodemes visible. Apodemes are straight axially, then angle posterolaterally laterally. Six, maybe seven, coxal holes on left side. Entire endophragm narrow, apparently straight sided.

Coxal bases closely spaced, making entire endophragm quite narrow. At least six thoracic appendages poorly preserved, segmentation not visible, terminations not visible.
Pleonal somites rectangular; 1 through 3 about same length, 4 and 5 about equal in length; sixth pleonite longer than others. Pleonite 4 narrower than others. Intestinal tract well preserved, narrow, packed with globular pellets posteriorly; pleonal somites well preserved; terga appear to be smooth; pleura strongly reduced, rounded rectangular, weakly rimmed, arcuate groove or rim anteriorly on somites, convex forward, directed posteroventrally in lateral view. Pleopods on somites 3,4 , and 5 appear to have long, narrow elements proximally.

Telson much longer than wide, margins weakly convex, narrowing slightly posteriorly, widest about one-third distance posteriorly. Telson short compared to uropods. Uropods very long, slender, outer margin entire, with straight diaeresis. Uropodal exopod anterior and posterior to diaeresis longitudinally striate for entire length.

Rectangular (cylindrical) objects surrounding the specimen may be fecal pellets.

Etymology.-The trivial name alludes to the extremely long, slender uropods.

Types.-Holotype LPI-41569, and paratypes LPI-41686, 41571, 41770, 41573, 32333, 41694, 32549, and 41696.

Remarks.-Three characters aligned these specimens to Eucopiidae: an antennal scale with a smooth outer margin, normal-sized eyes, and uropods with a smooth outer surface. Beyond those characters, Yunnanocopia longicauda also bears some resemblance to its congener, $Y$. grandis, so that placement in the same genus is warranted. The two species share a lanceolate to ovate antennal scale with acute tip, an antennular base with the first segment larger than the others, a precervical groove that does not cross the midline, a concave-forward cervical groove, strongly reduced to absent pleonal pleura, and no indication of setae on the tail fan.

The relative size of elements two and three in the antennular base is different in the two species in that the third element is small and triangular in $Y$. grandis (Fig. 8.2), whereas that in Y. longicauda (Fig. 8.3) is approximately the same size as the second element and has a more rounded terminus. The antennal scale on $Y$. longicauda is broader and has a thickened outer margin, whereas the antennal scale is narrower and not obviously thickened on the margin of $Y$. grandis. The endophragm of $Y$. grandis is weakly convex laterally, whereas that of $Y$. longicauda is straight sided, corresponding to the overall shape of the organisms in that $Y$. grandis is more stout than the slender $Y$. longicauda. Ornamentation of nodes on the terga of $Y$. grandis contrasts with the smooth tergal surface of $Y$. longicauda. Reduced pleura are present on Y. longicauda, but are not evident on $Y$. grandis. Pleonite 6 is shorter on $Y$. grandis than on $Y$. longicauda, although that structure is longer than the other pleonites in each species (Fig. 8.2, 8.3). The telson of $Y$. grandis is long and spatulate and that of $Y$. longicauda is shorter and more rounded at the tip. The length of the uropods of the former is shorter than that of the latter.

Clearly, the two forms are distinctly different morphologically. In addition, $Y$. grandis is less numerous and occurs as isolated individuals in the Luoping assemblage, whereas $Y$. longicauda is more numerous and occurs as swarms 


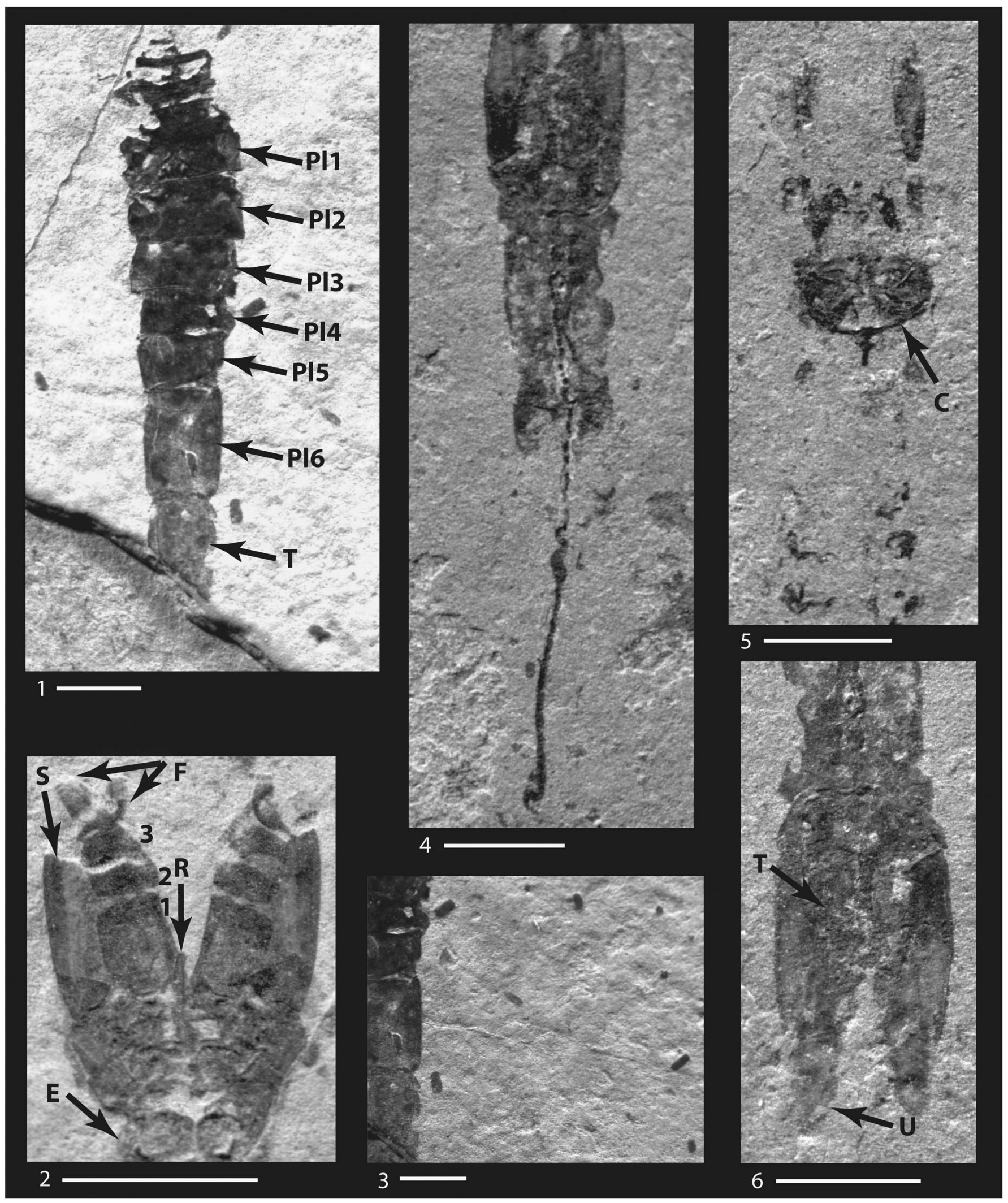

Figure 5. Yunnanocopia longicauda new genus new species: (1-3) LPI-41569, holotype, pleon, pleonites 1-6 labeled (Pl1-Pl6), note pleonite 6 much longer than others, telson (T) poorly preserved; (2) anterior view of well-preserved cephalic appendages, $\mathrm{S}=$ antennal scale, antennular basal segments 1 , 2 , 3 , $\mathrm{F}=$ antennular flagellae, $\mathrm{R}=$ rostrum, $\mathrm{E}=$ eye; $(\mathbf{3})$ fecal pellets associated with specimen, assumed to have been made by the same species; (4-6) LPI-41571, paratype, (4) posterior thorax and pleon showing trace of intestine; (5) anterior view of poorly preserved antennal scales and cervical groove (C); (6) telson (T) and uropods (U). Scale bars $=1 \mathrm{~mm}$. 


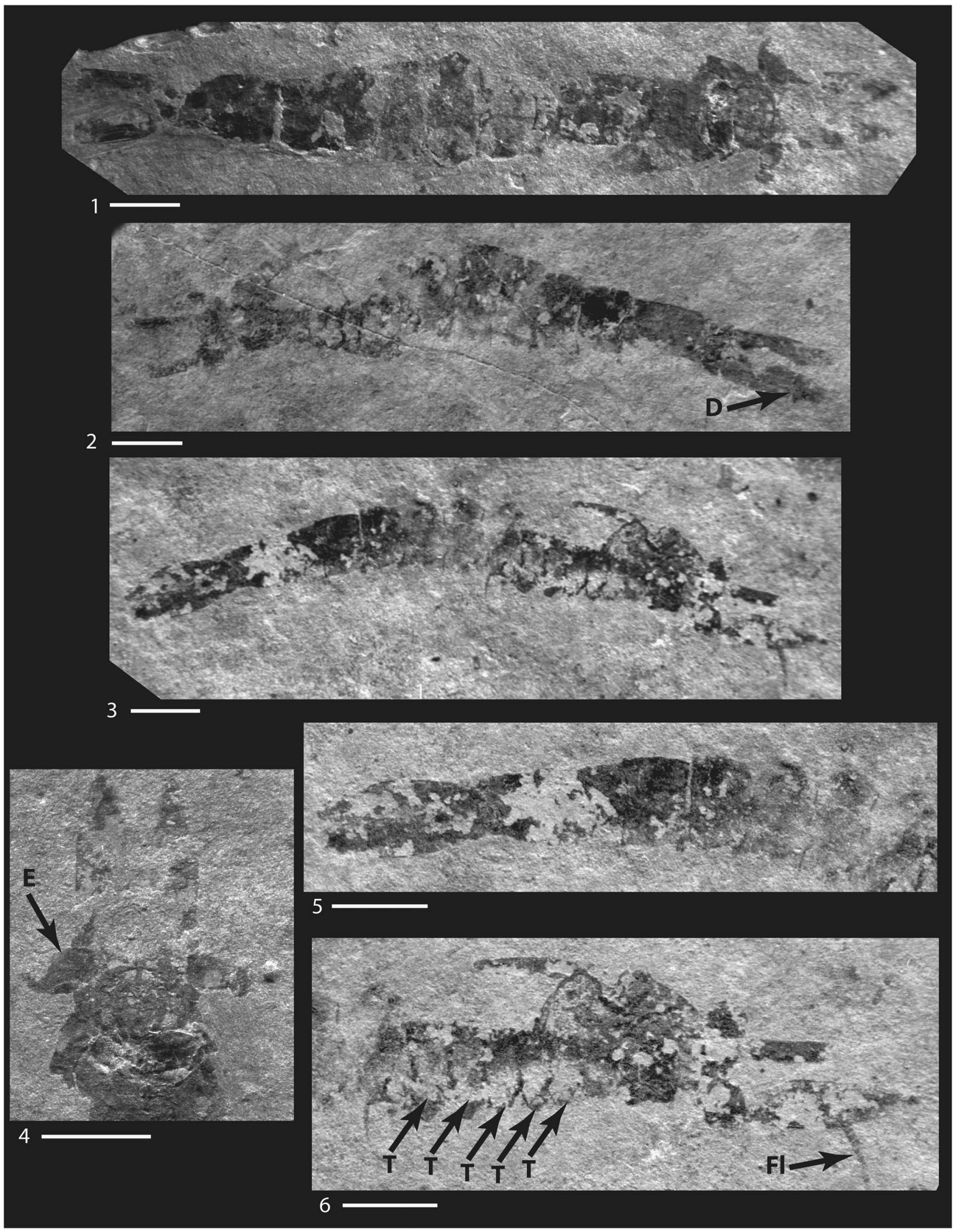

Figure 6. Yunnanocopia longicauda new genus new species: $(\mathbf{1}, \mathbf{4})$ LPI-41691, paratype, $(\mathbf{1})$ entire animal and (4) anterior view showing stalked eye (E); (2) LPI-41573, paratype, entire animal showing diaeresis (D) on exopod of uropod; $(\mathbf{3}, \mathbf{5}, \mathbf{6})$ LPI-41770, paratype, (3) entire animal; (5) pleon; (6) anterior view with antennal? flagellum $(\mathrm{Fl})$ and thoracic somites $(\mathrm{T})$. Scale bars $=1 \mathrm{~mm}$. 


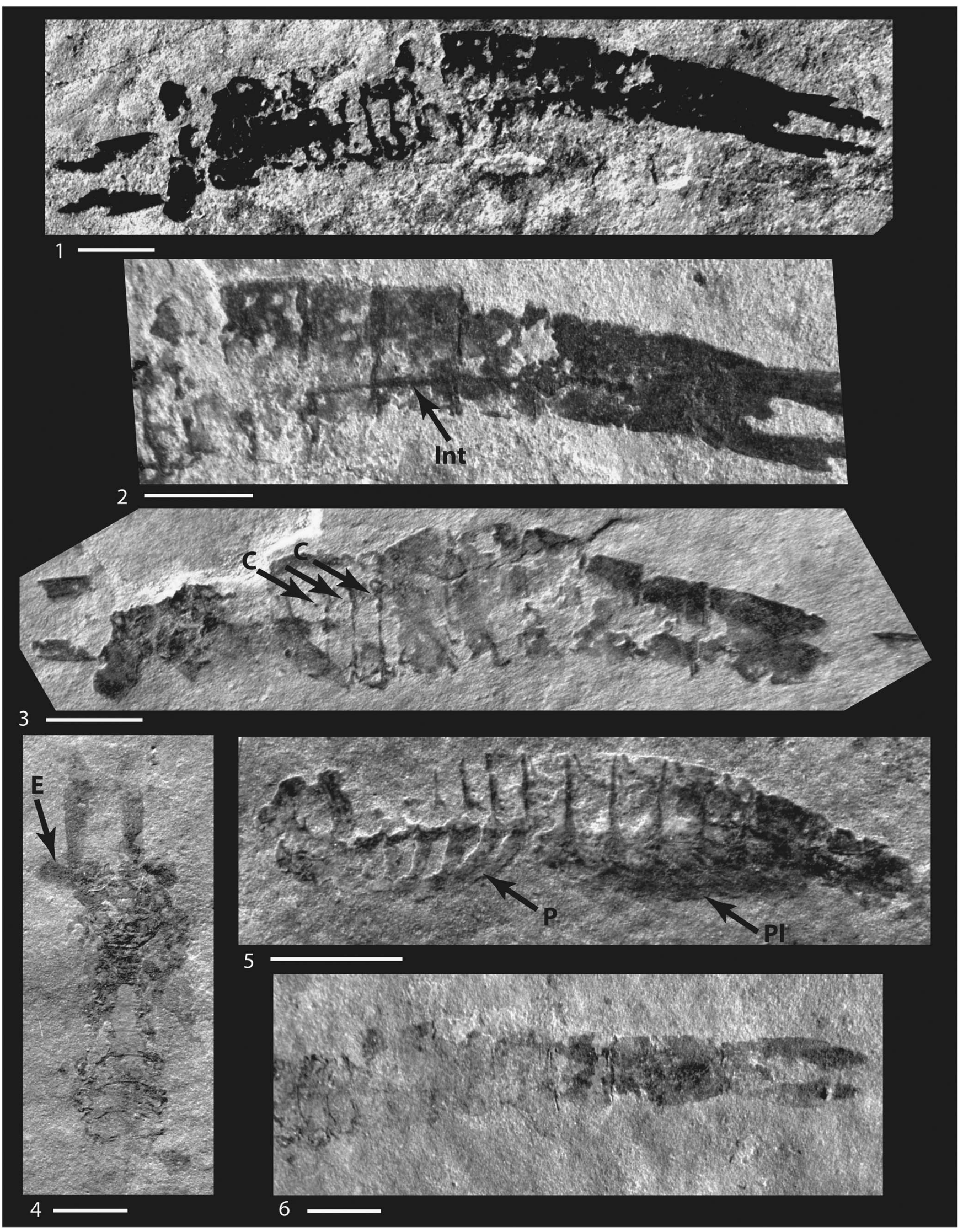

Figure 7. Yunnanocopia longicauda new genus new species: (1-2) LPI-41686, paratype, (1) entire animal, (2) pleon with intestinal trace (Int); (3) LPI-32393, paratype, most of animal with coxal bases marked (C); (4, 6) LPI-41696, paratype, (4) anterior view with stalked eye (E) and antennal scales; (6) posterior view of pleon and tailfan; (5) LPI 32549, paratype, lateral view of bases of thoracic appendages $(\mathrm{P})$ and pleopods $(\mathrm{Pl})$. Scale bars $=1 \mathrm{~mm}$. 


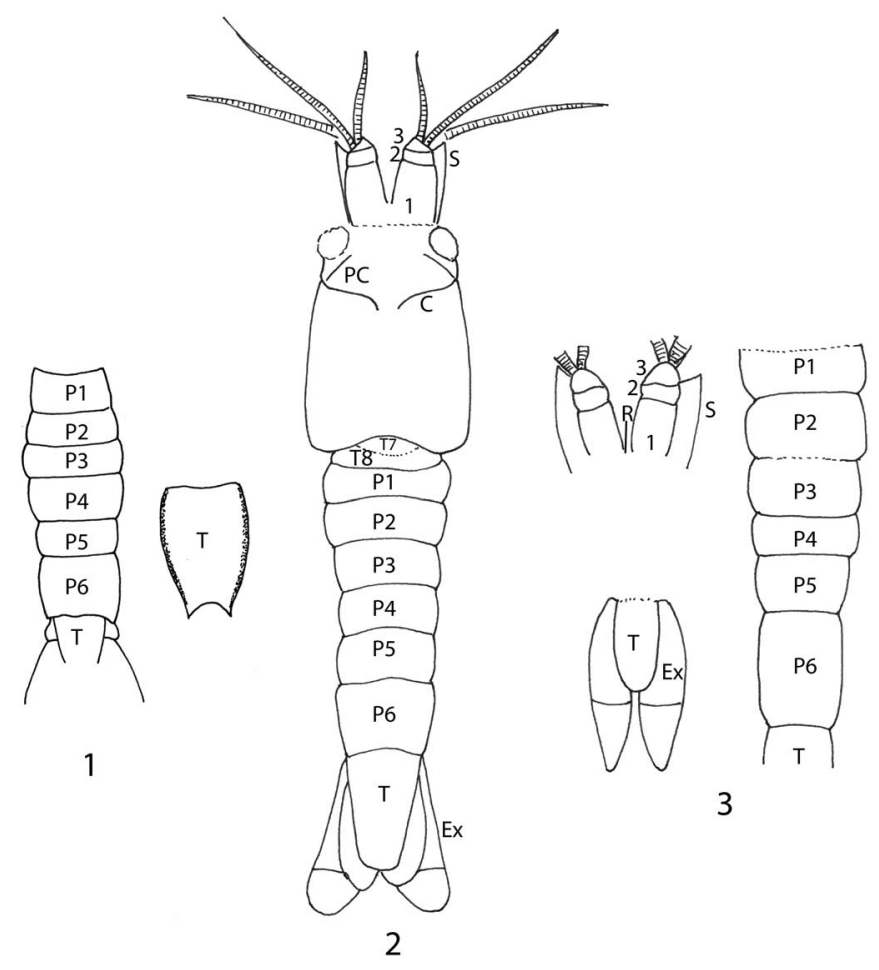

Figure 8. (1) Reconstruction of Eucopiidae species indeterminate. (2) Reconstruction of Yunnanocopia grandis new genus new species. (3) Reconstruction of Yunnanocopia longicauda new genus new species. $\mathrm{C}=$ cervical groove, $\mathrm{Ex}=$ exopod of uropod, $\mathrm{PC}=$ pre-cervical groove, $\mathrm{P} 1-$ $\mathrm{P} 6=$ pleonites $1-6, \quad \mathrm{R}=$ rostrum, $\mathrm{S}=$ antennal scale, $\mathrm{T}=$ telson, $\mathrm{T} 7-$ T8 $=$ thoracic somites 7 and $8,1-3=$ articles $1-3$ of basal element of antennule. Drawings not to scale.

(Fig. 9). The presence of a rostrum on $Y$. longicauda is problematic. An elongate structure is present on LPI-41569, however it is displaced slightly from the longitudinal axis and its relationship to the carapace is not clear. The feature is called out (Fig. 5.2), but its identity must be questioned. No similar structure is evident on other specimens.

The question remains to be resolved as to whether these differences warrant assignment to different genera or whether they can be united into a single genus. Examination of the form of the antennular base of three species of the extant EucopiaE. australis Dana, 1852, E. grimaldii Nouvel, 1942, and E. linguicauda Tattersall, 1955-demonstrates the third basal element is vastly different in the three species. That element on E. australis widens distally in concave arcs, and terminates in a broad, digitate margin. The third element on E. linguicauda is similar in having a digitate margin, but it forms the outer side of a triangular element. The third element of E. grimaldii is somewhat smaller, triangular, and the outer margin is undulose, rather than digitate. The shape of the carapace and the relative difference in length of pleonite 6 on the extant E. sculpticauda and E. unguiculata also differ markedly. Pleonite 6 is 1.6 times as long as pleonite 5 in E. sculpticauda, and 3.5 times as long as pleonite 5 in E. unguiculata. Pleonite 6 is 1.5 times as long as pleonite 5 in Yunnanocopia grandis and 2.2 times as long as pleonite 5 in $Y$. longicauda. The range in variation of morphology exhibited by $Y$. grandis and $Y$. longicauda compares well with that seen in extant species

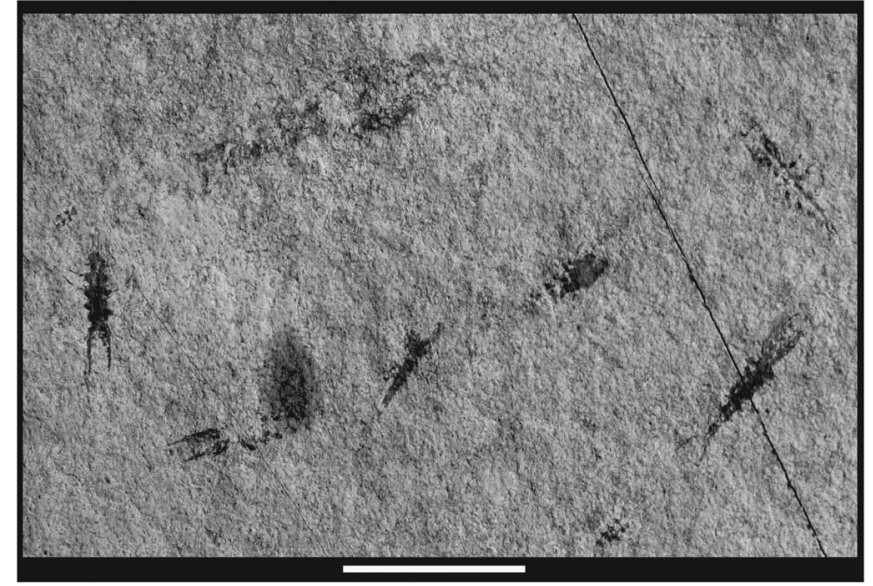

Figure 9. Swarm of Yunnanocopia longicauda new genus new species. Scale bar $=1 \mathrm{~cm}$

of Eucopia. Thus, we place the two species within a single genus until additional information warrants creation of a second genus.

Eucopiidae, species indeterminate

Figures 10.1-10.5, 11.1-11.5

Description.-Small eucopiid. Carapace appears to be short relative to pleon, poorly preserved. Oostegites with arcuate, thickened anterior rims, disarticulated.

Pleon with six pleonites in ventral view; pleonite 1 is shorter than 2, 2 is shorter than 3, 3 slightly longer than 4, 4 and 5 same length, 6 appears longer than 5; Pleon nearly equal width for entire length. Width is $32 \%$ length excluding telson.

Apodemes weakly convex forward, becoming concave forward at lateral margins. Pleon is about twice as long as cephalothorax. Each somite is rimmed posteriorly.

Telson and uropods not well preserved. Telson seems to be longer than wide, quadrate, weakly convex lateral margins, with tiny, sharp spines at posterolateral corners. Uropods with broad, ovate basal segment, longer than wide. Endopod and exopod extend beyond tip of telson. Outer edge of exopod of uropod with thickened rim, may be serrate proximally. Uropods appear to have longitudinal striations.

\section{Materials.-LPI-32802 (part), 41335a, 42567, RMFCES1, RMFCES2, RMFCES 3, RMFCES4-1, RMFCES4-2, RMFCES4-3.}

Remarks.-Nine specimens examined in detail were used to frame the above description. The specimens are small and invariably incomplete, so that framing a description sufficient to erect an additional species is not prudent. The specimens do exhibit characters that distinguish them from Yunnanocopia grandis and $Y$. longicauda. The pleuron, which is longer than the poorly preserved carapace, has convex lateral margins, so that the widest part of the pleon is at pleonite 3 . The telson is longer than wide, has convex lateral margins, and bears tiny spines on the posterolateral corners. The uropods are incompletely preserved only, suggesting that they are as long as, or 


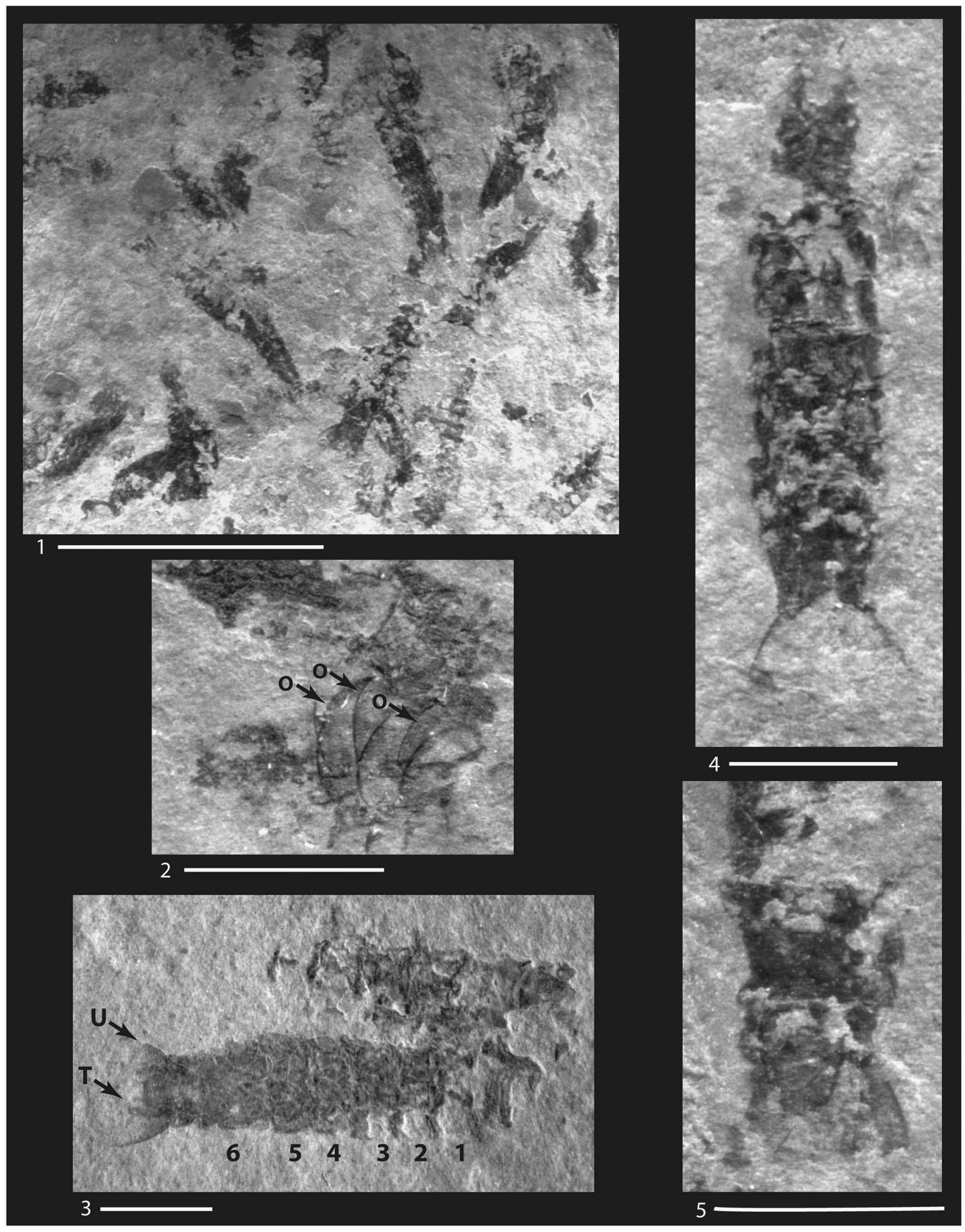

Figure 10. Eucopiidae species indeterminate: (1) LPI-32802, swarm of specimens in typical occurrence for taxon; (2) LPI-32802.3, possible marsupium, o = oostegite; (3) LPI-32802.1, pleon, 1-6 = pleonal somites, T = telson, U = uropod; (4) LPI-32802.2, pleon; (5) LPI-32802.4, posterior pleon and telson. Scale bar $1=5 \mathrm{~mm}$; remainder $=1 \mathrm{~mm}$. 

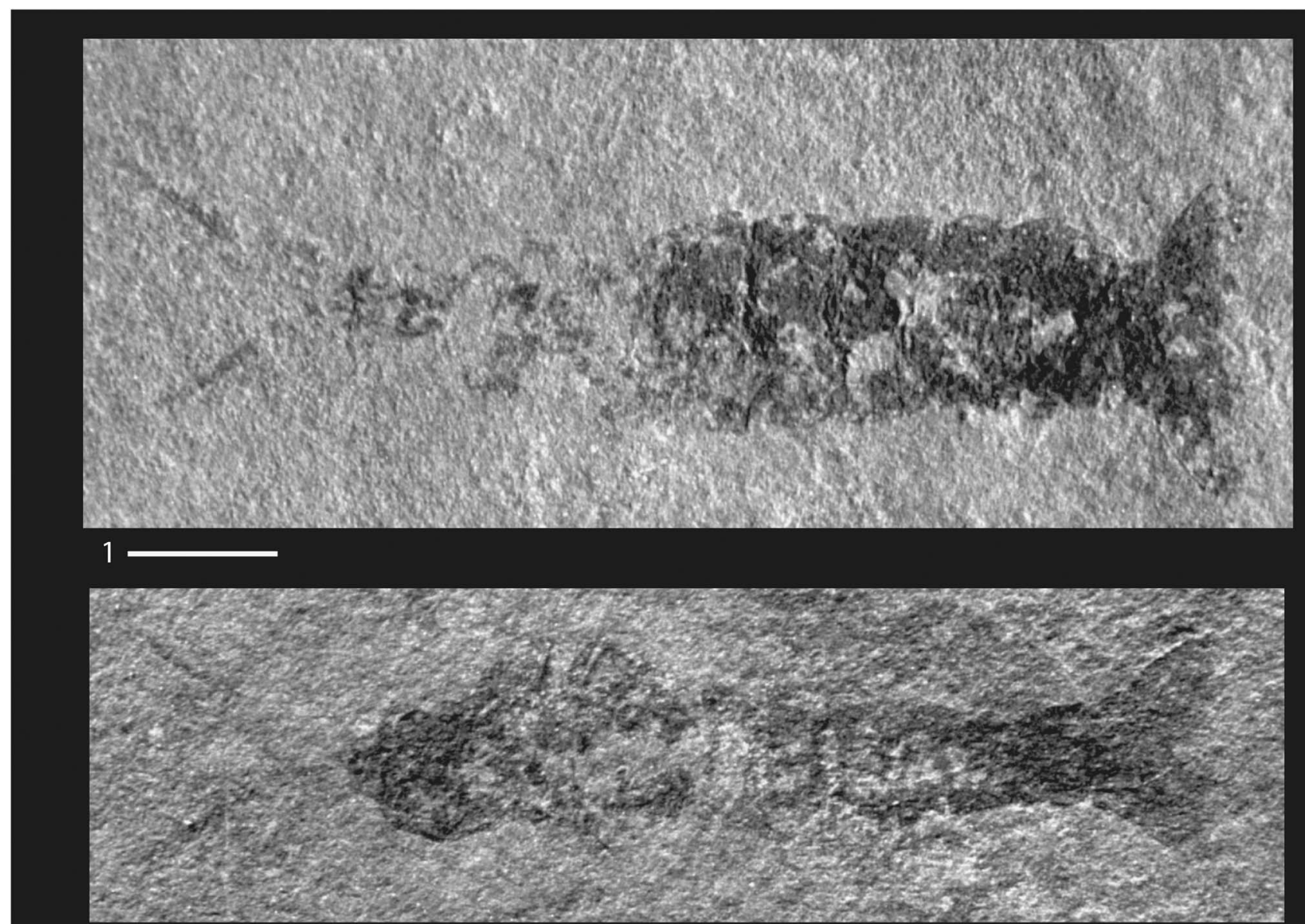

2

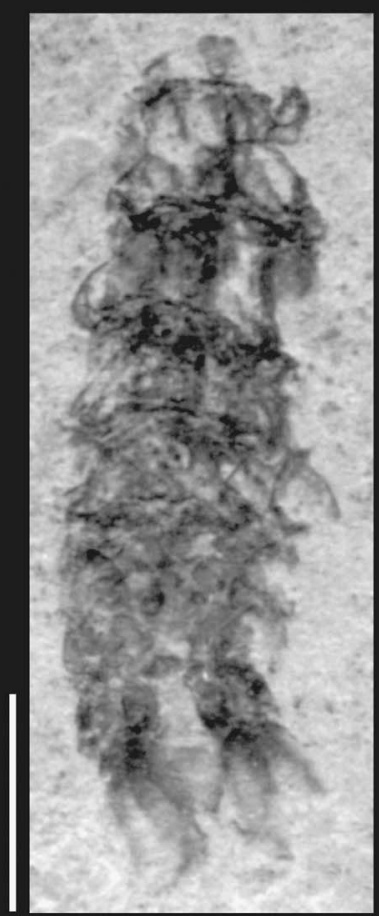

3

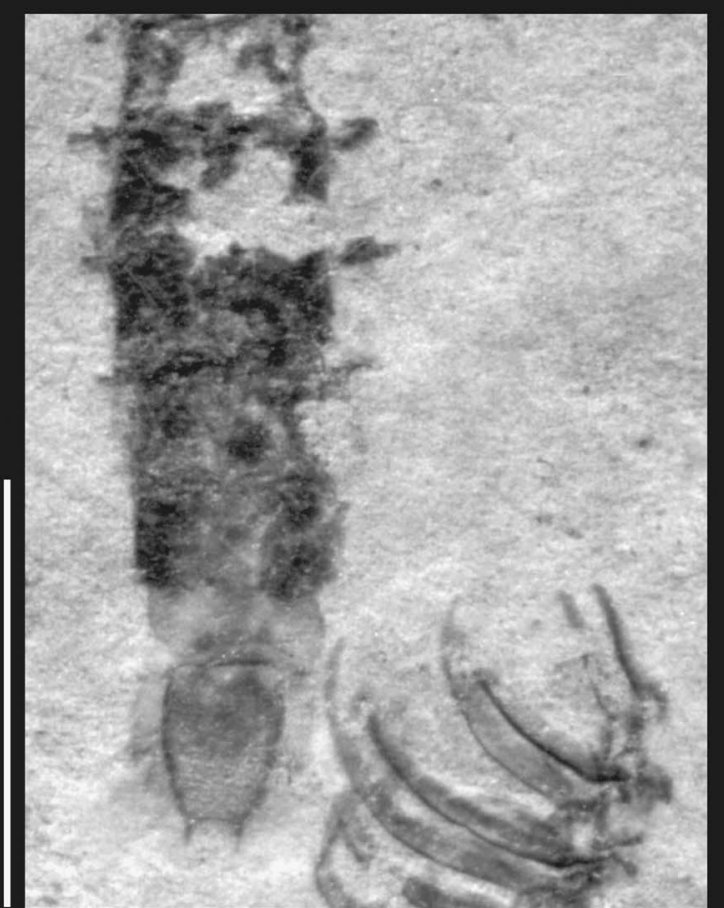

4

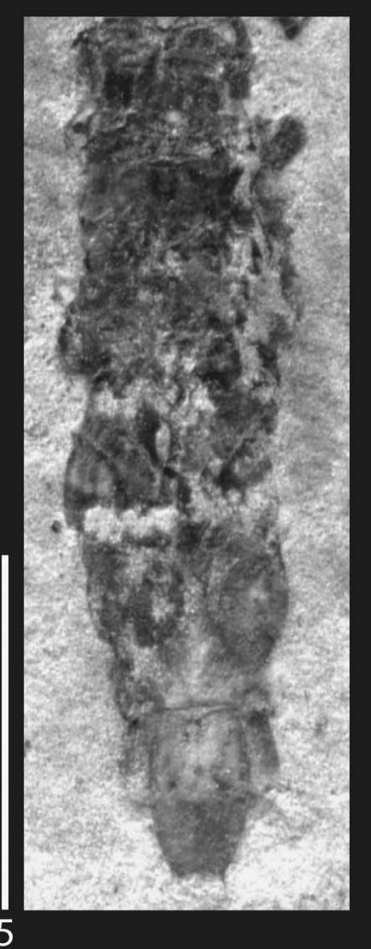

5

Figure 11. Eucopiidae species indeterminate: (1) 41335, entire animal showing short thorax and wide pleon; (2) 41335a, entire animal showing short thorax and wide pleon; (3) RMFCES3, pleon with well-preserved telson and uropods; (4) RMFCES4-1, pleonal somites and possible marsupium; (5) RMFCES4-2, pleon and well-preserved telson. Scale bars $=1 \mathrm{~mm}$. 
longer than the telson. This combination of characters, particularly the outline of the pleuron and the morphology of the telson, are significantly different from the two named species. This species occurs in swarms of dozens of individuals (Fig. 10.1).

\section{Reproduction}

Taylor et al. (2001) observed that little could be said about the reproductive strategy of Schimperella acanthocercus because there was no evidence of brooding structures in their specimens of that genus. However, examination of the illustrations of S. kessleri Bill, 1914 (pl. 16, figs. 3, 4) clearly illustrate an extended marsupium with what appear to be seven oostegites (Fig. 12.1). No such structures are illustrated on S. beneckei suggesting that it was based upon a male and that $S$. kessleri was based upon a female. As originally suggested by Briggs et al. (1993, p. 331), those specimens originally considered to represent two species should be assigned to a single species. By virtue of page priority, $S$. beneckei becomes the senior synonym and $S$. kessleri is its junior synonym.

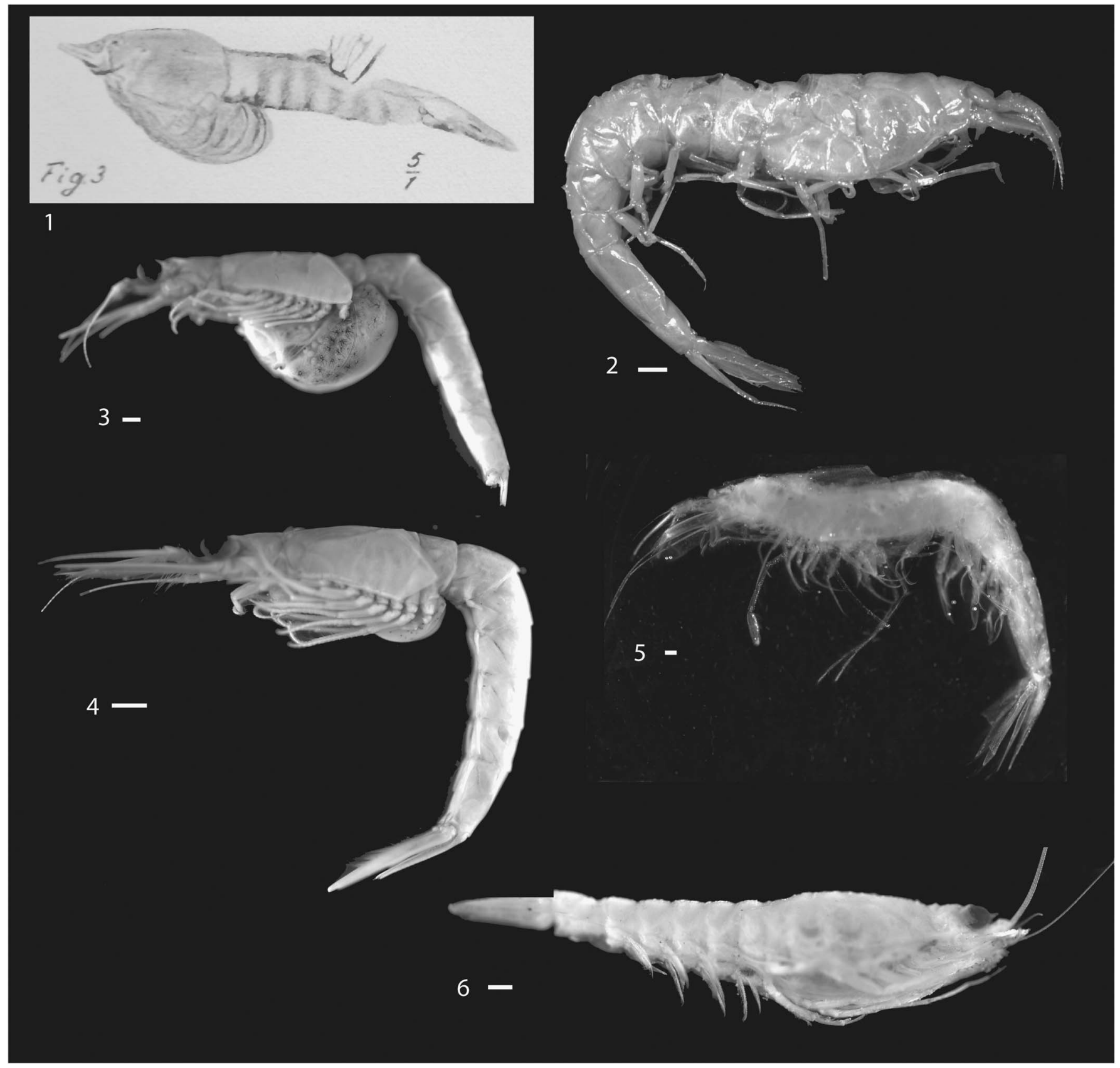

Figure 12. Mysidacea: (1) Lophogastrida, Eucopiidae, Schimperella kessleri, digital image of Bill (1914, pl. 16, fig. 3), showing probable marsupium of probable female; (2) Lophogastrida, Eucopiidae, Eucopia unguiculata, USNM 89756, lateral view, illustrating extremely thin, delicate cuticle; (3) Mysida, Mysidae, Mysis stenolepis, USNM 89733, female with well-developed marsupium; (4) Mysida, Mysidae, Mysis stenolepis, USNM 89732, female with marsupium tucked under thorax; (5) Lophogastrida, Eucopiidae, Eucopia major, USNM 283731, lateral view; (6) Lophogastrida, Lophogastridae, Lophogaster challengeri, USNM 235398, female with marsupium. Scale bars $=1 \mathrm{~mm}$. 
Structures interpreted to be oostegites are present on specimens of Yunnanocopia grandis (Fig. 4.1, 4.2). Although specimens of extant, gravid Eucopia could not be located in the collections of the Smithsonian Institution, representatives of Mysis stenolepis Smith, 1873, were available. One specimen, USNM 89733, exhibits a fully distended marsupium, in which eggs were visible (Fig. 12.3). Mysis Latreille, 1802, is the type genus of Mysidae, and that family is characterized by species bearing a reduced number of oostegites, generally three. Another M. stenolepis, USNM 89732, bore a marsupium, but it was tucked beneath the thorax (Fig. 12.4). Additionally, within the Lophogastrida, a specimen of Lophogaster challenger Fage, 1942, USNM 235398, (Fig. 12.6) carries a marsupium bearing more than three oostegites, as would be anticipated in species within Eucopiidae.

\section{Paleoecological implications}

Extant lophogastrids are marine pelagic organisms that are largely confined to habitats below $200 \mathrm{~m}$ (Wittmann et al., 2014). Studies summarized therein documented species of Eucopia Dana, 1852, at depths greater than $2000 \mathrm{~m}$. The fragile carapace and pleon of specimens of Eucopia spp. may suggest adaptation to great depth (Fig. 12.2, 12.5). Thus, although some Mysida occupy marine environments from tide pools to abyssal depths (Wittmann et al., 2014, and references therein), the lophogastrids currently are not known to inhabit epipelagic settings. Although species of Yunnanocopia in all probability did not inhabit bathyal depths, it may be inferred that they did not occupy the surface plankton but, instead, swarmed over middepth to bottom-water areas. Taylor et al. (2001, p. 310) referred to the mysidaceans, including lophogastrids, as preferring benthic habitats; but, current literature referred to above documents a pelagic lifestyle.

It is of note that Yunnanocopia is represented by two and possibly a third species. This is not unusual for eucopiids. Deepwater trawls in the mid-Atlantic frequently sample three species of Eucopia: E. grimaldii, E. sculpticauda, and E. unguiculata (personal communication, K. Meland, 2015). Thus, the discovery of two or three species of eucopiids in the Luoping Biota suggests that grouping of species is a behavior that has persisted since their early history.

\section{Acknowledgments}

Specimens forming the basis for the study were collected with the support of NSF OISE-1126137 to Feldmann and Schweitzer, National Geographic Society Grant 9128-12 to Feldmann, and China Geological Survey grants 121201114068001 and 1212011140051 to $\mathrm{Hu}$ and colleagues at Chengdu. Access to the spirit collections and facilitation of a loan of specimens for the research were provided by R. Lemaitre and K. Reed, United States National Museum, Smithsonian Support Center. Careful reviews by K. Meland, University of Bergen, Norway, and an anonymous reviewer substantially improved the manuscript. Associate Editor B. Pratt, University of Saskatchewan, also offered numerous constructive comments.

\section{References}

Bill, P.C., von, 1914, Über Crustaceen aus dem Voltziensandstein des Elasses: Mitteilungen der Geologischen Landesanstalt von Esla $\beta$-Lothringen, p. 289-338.

Boas, J.E.V., 1883, Studien über die Verwandtschaftsbeziehungen der Malakostraken: Morphologisches Jahrbuch, v. 8, p. 485-579.

Briggs, D.E.G., Weedon, M.J., and Whyte, M.A., 1993, Chapter 18, Arthropoda (Crustacea excluding Ostracoda), in Benton, M.J., ed., The Fossil Record 2: London, Chapman \& Hall, p. 321-342.

Dana, J.D., 1852, Crustacea, Part 1: United States Exploring Expedition during the years 1838-1842 under the command of Charles Wilkes, U.S.N., v. 13: Philadelphia, C. Sherman, 685 p.

Fage, L., 1942, Mysidacea-Lophogastrida. II: Dana Reports, v. 4, n. 23, p. $1-67$.

Feldmann, R.M., Schweitzer, C.E., Hu, S., Zhang, Q., Zhou, C., Xie, T., Huang, J., and Wen, W., 2012, Decapoda from the Luoping biota (Middle Triassic) of China: Journal of Paleontology, v. 86, p. 425-441.

Feldmann, R.M., Schweitzer, C.E., Hu, S., Huang, J., Zhou, C., Zhang, Q., Wen, W Xie, T., and Maguire, E., 2016 [2015], Spatial distribution of Crustacea and associated organisms in the Luoping biota (Anisian, Middle Triassic), Yunnan Province, China: evidence of periodic mass kills: Journal of Paleontology, v. 89, p. 1022-1037. DOI: http://dx.doi.org/10.1017/jpa.2015.60.

Fu, W.-L., Wilson, G.D.F., Jiang, D.-Y., Sun, Y.-L., Hao, W.-C., and Sun, Z.-Y., 2010, A new species of Protamphisopus Nicholls (Crustacea, Isopoda, Phreatoicidea) from Middle Triassic Luoping Fauna of Yunnan Province, China: Journal of Paleontology, v. 84, p. 1003-1013.

Haworth, A.H., 1825, XXIX. A new binary arrangement of the macrurous Crustacea: The Philosophical Magazine and Journal, London, v. 65 (323), p. 183-184.

Hessler, R.R., 1969, Peracarida, in Moore, R.C., ed., Treatise on Invertebrate Paleontology, Part R Arthropoda 4 (1): Boulder, Colorado and Lawrence, Kansas, The Geological Society of America, University of Kansas, p. R360-R393.

Hu, S., Zhang, Q., Chen, Z., Zhou, C., Lü, T., Xie, T., Wen, W., Huang, J., and Benton, M.J., 2011, The Luoping biota: exceptional preservation, and new evidence on the Triassic recovery from end-Permian mass extinction: Proceedings of the Royal Society B, Biological Sciences, v. 278, p. 2274-2282.

Križnar, M., and Hitij, T., 2010, Nevretenčarji (Invertebrates) Strelovške formacije, in Hitij, T., et al., eds., The Kingdom of Tethys, the Fossilized World of Triassic Vertebrates from the Kamnič-Savinjske Alps: Scopolia Supplement 5, p. 91-107.

Larghi, C., and Tintori, A., 2007, First record of a decapod from the Meride Limestone: new data from one of the best Ladinian (Middle Triassic) taphonomic windows of a transitional environment: Memorie della Societa Italiana di Scienze Naturali e del Museo Civico di Storia Naturale di Milano, v. 35 , p. $68-69$

Latreille, P.A., 1802-1803, Histoire naturelle, générale et particulière, des Crustacés et des Insectes, v. 3: Paris, F. Dufart, p. 1-468.

Luo, M., Chen, Z.Q., Hu, S.X., Zhang, Q.Y., Benton, M.J., Zhou, C.Y., Wen, W and Huang, J.Y., 2013, Carbonate reticulated ridge structures from the early middle Triassic of Luoping area, Yunnan, Southwest China: geobiologic features and implications for exceptional preservation of the Luoping biota: Palaios, v. 28, p. 541-551.

Martin, J.W., and Davis, G.E., 2001, An updated classification of the Recent Crustacea: Natural History Museum of Los Angeles County Science Series, v. 39 , p. $1-124$.

Meland, K., 2002, Mysidacea: Families, Subfamilies, and Tribes Version 1: 2 October 2000: Available from http://crustacea.net/crustace/mysidacea/ index.htm. (accessed July 2016)

Meland, K., and Willassen, E., 2007, The disunity of "Mysidacea" (Crustacea): Molecular Phylogenetics and Evolution, v. 44, p. 1083-1104.

Meland, K., Mees, J., Porter, M., and Wittmann, K.J., 2015, Taxonomic Review of the orders Mysida and Stygiomysida (Crustacea, Peracarida): PloS ONE, v. 10: e 0124656. doi:10.1371/journal.pone.0124656.

Norman, A.M., 1892, On British Mysidae, a family of Crustacea Schizopoda: Annals and Magazine of Natural History (6), v. 10, p. 143-166, 242-263, pls. 9,10

Nouvel, H., 1942, Sur la systématique des espèces du genre Eucopia Dana, 1852 (Crust. Mysidacea): Bulletin de l'Institute Océanographique, Monaco, v. 818, p. $1-8$.

Sars, G.O., 1870, Carcinologiske bidrag til Norges fauna. I. Monographi over de ved Norges kyster forekommende mysider. Første hefte: Christiania [Oslo], Brøgger \& Christie's bogtrykkeri, 64 p., pls. 1-5.

Sars, G.O., 1885, Report on the Schizopoda collected by the HMS Challenger during the years 1873-1876, in Nartes, G.S., ed., Report on the Scientific Results of the Voyage of the H.M.S. Challenger during the years 18731876. Zoology, v. 13, n. 37: London, Longmans \& Co., p. 1-228, pls. 1-38. Schram, F.R., 1986, Crustacea: New York, Oxford Press, 606 p. 
Schweitzer, C.E., Feldmann, R.M., Hu, S., Huang, J., Zhou, C., Zhang, Q., We, W., and Xie, T., 2014, Penaeoid Decapoda (Dendrobranchiata) from the Luoping biota (Middle Triassic) of China: systematics and taphonomic framework: Journal of Paleontology, v. 88, p. 457-474.

Smith, S.I., 1873, Report upon the invertebrate animals of Vineyard Sound and the adjacent waters, with an account of the physical characters of the region: Report of the U. S. Fish Commissioner of Fish and Fisheries, 1871 and 1872, p. 295-747.

Tattersall, O.S., 1955, Mysidacea: Discovery Reports, v. 55, p. 1-90

Taylor, R.S., Schram, F.R., and Shen, Y.-B., 2001, A new upper Middle Triassic shrimp (Crustacea: Lophogastrida) from Guizhou, China, with discussion regarding other fossil "mysidaceans": Journal of Paleontology, v. 75, p. $310-318$.
Wittman, K.J., Ariani, A.P., and Lagardère, J.-P., 2014, Chapter 54: Orders Lophogastrida Boas, 1883, Stygiomysida Tchindonova, 1981, and Mysida Boas, 1883 (also known collectively as Mysidacea), in von Vaupel Klein, J.C., Charmantier-Daures, M., and Schram, F.R., eds., Treatise on Zoology Anatomy, Taxonomy, Biology The Crustacea, Vol. 4, Part B: Leiden, Brill, p. 189-396.

Zhang, Q.Y., Zhou, C.Y., Lu, T., Xie, T., Lou, X.Y., Liu, W., Sun, Y.Y., and Jiang, X.S., 2008, Discovery and significance of the Middle Triassic Anisian biota from Luoping, Yunnan Province: Geological Review, v. 54, p. 145-149. [In Chinese]

Accepted 11 July 2016 